А. С. Насибулина, Л. В. Мантатова. Эколого-этические основы национальной стратегии устойчивого развития: опыт Японии

УДК 322.14

DOI: $10.18101 / 1994-0866-2019-1-39-44$

\title{
ЭКОЛОГО-ЭТИЧЕСКИЕ ОСНОВЫ НАЦИОНАЛЬНОЙ СТРАТЕГИИ УСТОЙЧИВОГО РАЗВИТИЯ: ОПЫТ ЯПОНИИ
}

\author{
(C) Насибулина Анастасия Сергеевна \\ научный сотрудник, \\ Восточно-Сибирский государственный университет \\ технологий и управления \\ Россия, 670013, г. Улан-Удэ, ул. Ключевская, 40В \\ E-mail: dn.nastia@gmail.com
}

\author{
(C) Мантатова Лариса Вячеславовна \\ доктор философских наук, профессор, \\ заведующая кафедрой философии, истории и культурологии, \\ Восточно-Сибирский государственный университет технологий и управления \\ Россия, 670013, г. Улан-Удэ, ул. Ключевская, 40В \\ E-mail: mantatovalarisa@mail.ru
}

\begin{abstract}
Национальные стратегии устойчивого развития являются координационными центрами для интеграции вопросов, связанных с окружающей средой в процессе принятия решений, а также для определения и реализации приоритетов в области устойчивого развития. Их значимость и ценность были определены три десятилетия назад. Основная задача национальных стратегий устойчивого развития заключается в том, чтобы воплотить слова в конкретные действия, которые помогут странам встать на путь устойчивого развития и идти в ногу со временем. Стратегии позволяют определить законодательные и институциональные механизмы реализации целей устойчивого развития. В статье рассматривается роль экологической этики в формировании национальных стратегий устойчивого развития; сделана попытка определить особенности экологической этики Японии, а также рассмотрено современное состояние стратегического устойчивого развития Японии.

Ключевые слова: устойчивое развитие; национальная стратегия устойчивого развития; экологическая этика; Япония; коэволюция; окружающая среда; цели устойчивого развития.
\end{abstract}

Для цитирования:

Насибулина А. С., Мантатова Л. В. Эколого-этические основы национальной стратегии устойчивого развития: опыт Японии // Вестник Бурятского государственного университета. Философия. 2019. Вып. 1. С. 39-44.

На конференции по окружающей среде и развитию в 1992 г. ООН впервые призвала все страны осуществлять стратегические и скоординированные действия в интересах устойчивого развития посредством разработки национальных стратегий устойчивого развития, они представляют собой инструмент, который правительства могут использовать для повышения эффективности принятия стратегических решений в интересах устойчивого развития ${ }^{1}$. Поскольку устойчивое развитие предполагает долгосрочный и комплексный подход, важное зна-

1 Agenda 21 [Повестка дня на XXI век] [Электронный ресурс]. URL:https://sustainabledevelopment.un.org/content/documents/Agenda21.pdf (дата обращения: 24.02.2019). 
чение имеет планирование, воплощенное в процессах формирования национальной стратегии. Стратегии дают возможность подвести итоги и определить приоритеты, а также сфокусироваться на проблемах, достичь консенсуса, изучить компромиссы и сделать выбор.

Национальные стратегии устойчивого развития служат для улучшения координации и интеграции политики в нескольких измерениях: горизонтально (между секторами политики), вертикально (между политическим и административным уровнями), во времени и между социальными секторами (государством, наукой, бизнесом, гражданским обществом). Национальные стратегии также стали понимать как средства для амбициозной реформы управления, объединяющей программу надлежащего управления и регулирования с принципами устойчивого развития: постепенно трансформировать процесс формирования национальной политики в направлении более эффективного многоуровневого управления; содействие переходу к открытости, прозрачности и участию общественности и заинтересованных сторон; совершенствование процессов, связанных с принятием решений, с тем чтобы решения принимались на основе убедительных доказательств и комплексного понимания последствий решения.

Экологическая этика как основа формирования стратегии устойчивого развития

Основным двигателем прогресса духовного сознания является экологическая этика, понятая как этика ответственности человека за вселенское бытие, за биосферу и ноосферу Земли. Первое прагматическое требование экологической этики состоит в поддержании функционирования всех структур и уровней (холонов) в космической иерархии [1]. К. Уилбер описывал суть подлинной экологической этики следующим образом: «Мы должны превзойти и включить в себя все холоны в истинном объятии. Поскольку в человеке есть материя, жизнь и разум сами по себе, то мы, конечно же, должны уважать эти холоны не только за их внутреннюю ценность, которая, безусловно, является самой важной, но также и потому, что они есть компоненты нашего собственного существа, и разрушение их убийственно и для нас. Неразумно причинять вред биосфере, ведь этот вред в конечном счете вернется к нам и будет разрушать нас извне. Ведь биосфера находится буквально внутри нас, является частью самого бытия, составной частью нашей индивидуальности. Разрушать биосферу — внутреннее самоубийство, а не только внешняя проблема» [2]. Основной императив экоэтики: надо всемерно поддерживать движение ноосферы, ибо в этом - залог устойчивого развития мира.

Основная задача экологической этики - выработка ценностнонормативных принципов взаимодействия человека с окружающей средой. Этот процесс предполагает две стадии - критическую и конструктивную. На первой происходит переосознание места природы в системе человеческих ценностей. Вторая связана с утверждением новых оснований жизнедеятельности человека [3].

По мнению профессора В. В. Мантатова, «экологическая этика представляет собой, возможно, единственный философский проект, который дает шанс человечеству сохранить себя в биосфере и во Вселенной. В этом расколотом мире нет другой парадигмальной платформы, на основе которой люди мира могли бы объединиться в целях обеспечения устойчивости «нашего общего будущего» [1]. 

вого развития: опыт Японии

Экологическая этика как аксиологическое основание устойчивого развития цивилизации дает возможность сформировать целостную стратегию коэволюции общества и природы.

Этика окружающей среды играет ключевую роль в регулировании взаимодействия человека с окружающей средой. Современная экологическая этика это философское переосмысление экологического поведения современного человечества. Устойчивое развитие подразумевает гармонию взаимодействия между человеком и окружающей средой. Гармоничное построение общества должно быть основано на экологической этике. Смысл экологической этики включает в себя уважение к природе, заботу о человечестве и уважение к будущим поколениям. Роль экологической этики в региональном развитии состоит в познании, критике, образовании, корректировке законодательства и продвижении экологических норм. Основными проблемами в региональном развитии являются истощение природных ресурсов, быстрый рост населения, нерациональная структура промышленности, несправедливое распределение благосостояния и последствия развития науки и техники. Экологическая этика в контексте разработки национальных или региональных стратегий устойчивого развития может не только гармонизировать отношения социума, окружающей среды и экономического развития, но также может стимулировать трансформацию социальной и политической системы, укреплять правовую систему и повышать экологическую сознательность общественности.

\section{Особенности японской экологической этики}

Японская экологическая этика как междисциплинарная область научного знания сложилась на основе религиозных, социально-политических, философских и научных традиций этики Японии.

Религиозная мысль сформировала японскую самоидентификацию относительно окружающей среды, но интересно то, что, хотя эти убеждения влияли и формировали уникальные социальные ценности, они сами по себе не сделали общество очень религиозным. Убеждения религиозные являются важным элементом в формировании этических или философских принципов. В Японии существует три традиционных набора духовных убеждений: синтоизм, буддизм и конфуцианство. Хотя многие японцы сегодня не практикуют активно определенную религию, верования синтоизма и буддизма все еще коренятся в их повседневной жизни, а конфуцианство продолжает выживать в постоянно меняющемся японском обществе [4].

Истоки современной японской экологической этики восходят к катастрофическому загрязнению окружающей среды Японии вскоре после Второй мировой войны. Решительное стремление Японии к промышленному росту с конца 1950-х по 1970-е годы в сочетании с нерегулируемой деятельностью крупных химических фабрик привело к четырем крупным вспышкам Kōgai (公害, загрязнение) (две вспышки болезни Минамата, болезнь Итай-итай и астма Йоккаити) [5]. Впоследствии в 2000-х гг. был разработан академический курс, известный как Minamata-gaku, по сути своей и являющейся японской экологической этикой. Minamata-gaku можно охарактеризовать следующими аспектами. Во-первых, это междисциплинарная область исследования, которая делает особый упор на ценность жизни; во-вторых, в нем рассматриваются обязанности бизнеса и правительства с целью найти причину и разрешить последствия экологического ущерба; в-третьих, и самое главное, Minamata-gaku - это дисциплина, основанная на 
японских эмпирических ценностях. Для нации, чей народ пережил катастрофические экологические проблемы и продолжает с ними сталкиваться, знания и опыт того, как преодолеть эти проблемы, создают философский фундамент, убедительный, чем теоретическая философская система убеждений [6].

Комплексный анализ религиозных, философских и научных оснований показывает, что именно их совокупность исторически способствовала формированию культурного своеобразия экологической этики Японии. Страна создала свою уникальную модель экологической этики, основанную на культурных традициях, религиозных практиках и эмпирическом опыте.

\section{Стратегия устойчивого развития Японии}

К XXI в. Япония превратилась из самой загрязненной в мире индустриальной страны в одну из самых экологически сознательных наций в мире. Политика Японии в области охраны окружающей среды развивалась благодаря развитию промышленности с 1945 г. до начала 1970-х гг. и развитию городов с начала 1970-х до конца 1980-х гг. Данные события послужили стимулом для формирования политики, контролирующей и сохраняющей качество природного мира Японии. Сегодня страна стремится быть не только экономической, но и «экологической» сверхдержавой, которая занимается вопросами обеспечения чистоты окружающей среды в обществе. Важным компонентом формирования японской экологической политики является экологическая этика.

Внутренняя природоохранная политика Японии разрабатывается с целью противодействия глобальным экологическим вызовам и развивается благодаря принятию законов и постановлений. Помимо этого, экологическая политика активно использует науку и технологии для решения проблем. Есть три основных органа, которые формируют внутреннюю экологическую политику Японии: Агентство по охране окружающей среды, позже ставшее Министерством окружающей среды, которое является ключевым органом экологической политики; Министерство международной торговли и промышленности, позднее переименованное в Министерство экономики, торговли и промышленности, - играет роль посредника между государством и бизнесом; Японская федерация бизнеса (Nippon Keidanren), промышленные корпорации и предприятий Японии, — вносят свой вклад в политику в области охраны окружающей среды на внутреннем рынке посредством саморегулирования [7]. Благодаря гармоничному и взаимовыгодному сотрудничеству этих трех игроков Япония успешно реализует и корректирует национальную стратегию устойчивого развития, стараясь сохранить гармонию между экономическим ростом и защитой окружающей среды.

Создание Агентства по охране окружающей среды в 1971 г. было знаменательным в том смысле, что впервые был сформирован главный государственный орган по контролю за загрязнением окружающей среды. Три десятилетия спустя Агентство было пересмотрено и переименовано в Министерство окружающей среды, его роль не сильно изменилась, но ответственность была расширена и усилена. Министерство окружающей среды играет центральную роль в разработке стратегии развития Японии [8]. В связи с принятием Повестки дня в области устойчивого развития на период до 2030 г. правительство Японии учредило в 2016 г. новый орган Кабинета министров - штаб-квартиру по продвижению целей устойчивого развития. Она была создана для развития тесного сотрудничества между соответствующими правительственными учреждениями, а также для обеспечения всестороннего и эффективного осуществления мер, связанных с це- 
лями устойчивого развития. В декабре 2016 г. были приняты «Руководящие принципы реализации целей устойчивого развития», которые представляют собой национальную стратегию Японии по решению основных задач в целях реализации Повестки дня на период до 2030 г. В руководящих принципах определено видение Японии будущего: «Стать лидером в будущем, где экономические, социальные и экологические улучшения достигаются комплексным, устойчивым образом, не оставляя никого позади». В Руководящих принципах определены восемь приоритетных областей, на которых должна сосредоточиться Япония с учетом национального контекста и перечислены конкретные меры, которые должны быть реализованы как внутри страны, так и на международной арене ${ }^{1}$.

Япония в числе первых стран стала осуществлять комплексные меры по созданию устойчивого общества на основе экологических, экономических и социальных улучшений. Япония приступила к созданию общества, открытого для всех, в котором каждый человек может полностью реализовать свой потенциал. В соответствии с этим идеалом Япония продвинулась вперед, реформировав соответствующие системы. Кроме того, Япония определила безопасность человека в качестве руководящего принципа. Основываясь на собственном опыте, Япония сыграла ведущую роль в разработке «Повестки дня на период до 2030 г.», включая индивидуальные цели и задачи. Япония стремится стать примером для всего мира в реализации мер по достижению целей устойчивого развития и прилагает усилия как внутри страны, так и в сотрудничестве с другими странами для создания устойчивых обществ во всем мире.

\section{Литература}

1. Мантатов В. В., Мантатова Л. В. Стратегия Человечества: ноосфера, информационная цивилизация и устойчивое развитие: монография. Улан-Удэ: Изд-во ВСГУТУ, 2016. $152 \mathrm{c}$.

2. Уилбер К. Краткая история всего / пер. с англ. С. В. Зубкова. М.: АСТ: Астрель, 2006. $476 \mathrm{c}$.

3. Гунзенова К. В., Мантатова Л. В. Институционализация устойчивого развития: монография. Улан-Удэ: Изд-во ВСГУТУ, 2016. 176 с.

4. 和辻哲郎全集. 第二次版 も同時刊行 [Watsuji T. Watsuji Tetsurō Zenshū (Collected works of Watsuji Tesurō)]. Vol.11. Tokyo: Iwanami Shoten, 1979. P. 385.

5. 原田,正純『いのちの旅「水俣学」への軌跡』東京新聞出版局、2002 年 11 月 [Harada M. Inochi no tabi - Minamata-gaku he no kiseki (The path of life, traced through Minamata-Studies)]. Tokyo: Tokyo Shimbun Shuppan-kyoku, 2002. 269 p.

6. Yoshimoto T. Chiisana sekai heno kaiki [The return to the small world]. Kankyō. 2003. Vol. 28. P. 8-9.

7. Imura H. Japan's environmental policy: past and future / H. Imura and M. Schreurs (eds.). Environmental policy in Japan, Edward Elgar. Massachusetts, 2005. P. 359.

8. Tsuru S. The Political Economy of the Environment: The Case of Japan (Bloomsbury Academic Collections: Japan) Bloomsbury Academic. 2013. 400 p.

${ }^{1}$ The SDGs Implementation Guiding Principles [Руководящие принципы реализации ЦУР] [Электронный ресурc]. URL: https://www.mofa.go.jp/files/000252819.pdf (дата обращения: 04.03.2019). 


\title{
ENVIRONMENTAL AND ETHICAL FOUNDATIONS OF A NATIONAL
} STRATEGY FOR SUSTAINABLE DEVELOPMENT: A CASE STUDY OF JAPAN

\author{
Anastasia S. Nasibulina \\ Research Assistant, \\ East-Siberian State University of Technology and Management \\ 40v Klyuchevskaya St., Ulan-Ude 670013, Russia \\ E-mail:dn.nastia@gmail.com
}

\section{Larisa V. Mantatova}

Dr. Sci. (Philos.), Prof., Head of Philosophy, History and Cultural Studies Department, East-Siberian State University of Technology and Management

40v Klyuchevskaya St., Ulan-Ude 670013, Russia

E-mail: mantatovalarisa@mail.ru

National sustainable development strategies are focal points for integrating the environment-related issues into the decision-making process, as well as for identifying and implementing sustainable development priorities. Their significance and value were established three decades ago. The main task of national sustainable development strategies is to translate words into actions that will help countries take the path of sustainable development and keep up with the times. Strategies make it possible to determine the legislative and institutional mechanisms for the implementation of sustainable development goals. The article discusses the role of environmental ethics in the creation of national sustainable development strategies. We have made an attempt to determine the peculiarities of ecological ethics of Japan, and reviewed the current state of Japan's strategic sustainable development.

Keywords: sustainable development; national sustainable development strategy; environmental ethics; Japan; coevolution; environment; sustainable development goals. 